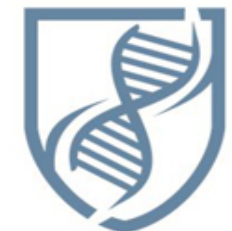

Journal of Bioscience and Applied Research
JBAAR

WWW.JBAAR.ORG

\title{
Some biochemical markers and expression of indoleamine-2, 3-dioxygenase in Egyptian patients with chronic Hepatitis $\mathrm{C}$
}

\author{
Salem, M.L. ${ }^{1}$, Barakat, L.A. ${ }^{2}$, Elnakeeb,N.A ${ }^{2}$, and Zeidan, A.A. ${ }^{1}$ \\ ${ }^{1}$ Immunology \& Biotechnology Division, Department of Zoology,Faculty of Science; Tanta University; Egypt \\ ${ }^{2}$ Biochemistry Section, Department of Chemistry,Faculty of Science, Port Said University; Egypt \\ (Corresponding author e.mail. mohamedlabibsalem@yahoo.com)
}

\begin{abstract}
Hepatitis C virus (HCV) is a main cause of chronic hepatitis and it may leads to cirrhosis, hepatic failure and hepatocellular carcinoma. Chronic HCV patients are subjected to treatment with ribavirin and interferon- $\alpha$ (IFN$\alpha$ ) but,which have achieved only limited success. The main aim of this study was to measure indoleamine-2, 3dioxygenase (IDO) in chronic HCV patients which could explain the failure from therapy. Five $\mathrm{ml}$ of peripheral blood were collected from 30 patients with chronic HCV infection and 10 healthy control volunteers. Patients were categorized in to responders and non-responders according to viral titre upon IFN- $\alpha$ treatment. The levels of IDO were measured in the sera of the recruited subjects. Significant increases $(\mathrm{P}<0.001)$ in the concentration of IDO were observed in IFN- $\alpha$ non-responder patient when compared with responders and healthy control. Conclusion: Nonresponsiveness of chronic HCV patients to IFNs based therapy associated with increases in suppressive mechanisms, opening a new avenue for targeting these molecules in HCV therapy.
\end{abstract}

Key words: Hepatitis C virus (HCV); Immune suppression; IFN- $\alpha$; ribavirin; Indoleamine 2, 3- dioxygenase (IDO).

\section{Introduction}

Hepatitis C virus (HCV) infection is one of the major causes of liver diseases(Mohd Hanafiah et al., 2013; Afdhal et al., 2014). HCV estimated 170-200 million infected persons globally, while Egypt has the rising rate of HCV infection, ranging from 6 to $28 \%$, with an average of approximately $13.8 \%$ in the general population(Mohamoud et al., 2013;
Cuadros et al., 2014). Since, the discovery of the virus, the backbone drug used in all antiviral protocols was interferon$\alpha$ (IFN- $\alpha$ ), that attains viral clearance in $40 \%$ of the patients while $60 \%$ fail this therapy, which does not attack the virus directly but stimulates the immune system and activated it to become more efficient to eliminate the virus(Trembling et al., 2013; Vasudevan and Lubel 2015). Recently, it has been discovered drugs such as sovaldi, which act directly on the virus life cycle to prevent proliferation of the virus, by attacking enzymes necessary to manufacture the parts of the virus or prevent it from entering the liver cell or block the necessary proteins required for the formation of the virus (Dhingra et al., 2014).

Tryptophan has been considered as the main amino acid for proliferation and activation of T- cells, in particular various cells as macrophages and multiple malignant cells have been found to express high levels of Indoleamine 2, 3 dioxygenase (IDO) (Yu et al., 2013). IDO is a heme containing, immunosuppressive enzyme that catalyse tryptophan to kynurenine(Platten et al., 2012; Lepiller et al., 2015; Asghar et al., 2015). Interferon- $\gamma$ (IFN- $\gamma$ ) cooperates with tumor necrosis factor (TNF), lipopolysaccharide (LPS) and interleukin-1 (IL- 1) to increase IDO expression [ (Yeung et al., 2012; Asghar et al., 2015). Various types of tumors expressed high levels of IDO which in turn prevent local T-cell dependent anti-tumor immunity and as a result promote tumor growth (Yu et al., 2011). Furthermore, IDO may inhibit the immunity of T-cells by stimulating both differentiation and maturation of CD4+CD25+ regulatory T cells. As such IDO has been implicated in modulation of disorders cancer and autoimmune diseases (Yu et al., 2011). Recent studies showed a positive correlation between tumor-induced immunosuppression and IDO ( $\mathrm{Yu}$ et al., 
2013). The suppressive effects of IDO is exerted via increase in suppressive metabolites at the tumor site as well decreasing the level of tryptophan (Yu et al., 2013).

Our study aimed to measure the expression of IDO in a population of Egyptian patients with chronic HCV in both responders and non-responders to IFN- $\alpha$ and ribavirin.

\section{Materials and Methods}

\subsection{Subjects:}

The research study was approved by the local ethics committee, Faculty of Medicine, Tanta University and informed consent was obtained from all patients before participation.The study was conducted among thirty patients with chronic HCV infection with a mean age of $44 \pm 4$.5. We also recruited healthy volunteers with a mean age of $39.5 \pm$ 4.51.Patients were recruited from the Tropical Medicine \& Infectious Diseases Department, Tanta University (Tanta, Egypt). Pegylated IFN- $\alpha$ (long acting interferon; Pegassys or Peg Intron) once every week for 48 weeks plus daily treatment with $800-1200 \mathrm{mg}$ ribavirinis considered the main treatment protocol which applies to the patients enrolled in this study.According to the clinical response, if no response occurs the treatment should stopped after 24 weeks from beginning the treatment course.

\subsection{Inclusion and exclusion criteria:}

The inclusion criteria of HCV patients before IFN- $\alpha$ treatment included the history of HCV infection and high levels of ALT. The exclusion criteria included coinfection or super infection with other hepatitis viruses.

\subsection{Measurement of viral load:}

Patients who were determined by positive for HCV by measuring HCV RNA level in their plasma using the transcription-mediated amplification quantification or real time PCR HCV quantification kits(Comanor et al., 2001)

\subsection{Detection of plasma human IDO:}

IDO concentrations in plasma were quantified by sandwich ELISA technique using (Ray Biotech) human IDO ELISA kit. All reagents, samples and standardswere prepared according to the recommended by the manufacture. Then, $(100 \mu \mathrm{l})$ standard and samplewere added to each well and incubated for 2 hours at $37^{\circ} \mathrm{C}$. After that, $(100 \mu \mathrm{l})$ prepared detection reagent A was aspirated, added and incubated for 1 hour at $37^{\circ} \mathrm{C}$. Then,prepared detection reagent $\mathrm{A}$ was aspirated and washed 3 times. After that, $(100 \mu \mathrm{l})$ prepared detection reagent Bwas added and incubated for 1 hour at $37^{\circ} \mathrm{C}$. Then,prepared detection reagent $\mathrm{B}$ was aspirated and washed 5 times. After that, $(90 \mu \mathrm{l})$ substrate solutionwas added and incubated for $15-25$ minutes at $37^{\circ} \mathrm{C}$. Finally, $(50 \mu \mathrm{l})$ stop solution was added. Then, read immediately at $450 \mathrm{~nm}$.

\subsection{Biochemical analysis:}

Liver functions were assessed by measured serum alanine aminotransferase (ALT), aspartate aminotransferase
(AST), total bilirubin, serum albumin were purchased from (Diamond)(Shaker et al., 2010).

\subsection{Statistical analysis:}

According to the viral titer the CHC patients were divided into groups; responders and non-responders. The clinical data were collected along the study and analyzed for each patient, each value was calculated as the mean \pm SD. Results were analyzed using a paired Student's t-test. ${ }^{*} P \leq$ 0.05 ( $P$ values below 0.05 were considered significant); significant differences were performed with a one way analysis of variance (ANOVA). Linear regression test was used to detect whether there is a correlation between the two quantitative variables.

\section{Results}

\section{IDO expression in chronic HCV patients:}

Significant increases in the levels of IDO were found in IFN- $\alpha$ non- responderCHC patients when comperd to responder patients $(P<0.001)$ and healthy voulenteers $(P<$ $0.01)$; $41.6 \pm 3.1,31.8 \pm 3.1$ and $19.6 \pm 0.5$, respectively as shown in Table 1 and Figure 1.

\section{Complete blood count (CBC) analysis in chronic HCV} patients:

In Table 2 significant decrease $(P<0.05)$ in the total numbers of white blood cellswere found in IFN- $\alpha$ responders and non- responder CHC patients when compared with the controls; $5.7 \times 103 \pm 0.5 \times 103,5.9 \times 10$ $3 \pm 0.3 \times 103$ and $7.4 \times 103 \pm 0.4 \times 103$, respectively as shown in Figure 2A. Also, significant decrease $(P<0.05)$ in the percentage of granulocytes were found in IFN- $\alpha$ responders and non- respondersCHC patients as compared with healthy controls; $46.6 \pm 3.2,47.7 \pm 3.4$ and $60.8 \pm 2.8$, respectively as shown in Figure 2D. In contrast, the increases in the percentage of monocytes and lymphocyteswere measuredin IFN- $\alpha$ responders and nonresponderCHC patients when compared with healthy controls; $5.8 \pm 0.2,5.0 \pm 0.3$ and $4.2 \pm 0.5$, respectively for

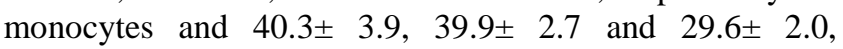
respectively for lymphocytes as shown in Figures 2 (C, B).

\section{Liver functions in chronic HCV patients:}

In Table 3the increases in ALT and AST activitieswere foundin IFN- $\alpha$ responders and non-responderCHC patients when compared with healthy controls of note there were no significant differences (31.4 $\pm 6.2,29.9 \pm 4.8$ and 25.1 \pm 2.1$)$ and (37.2 $\pm 4.5,33.2 \pm 4.9$ and 27.1 \pm 1.1 ), respectively as shown in Figure 3 (A, B). However, total bilirubin levels were significantly increased $(P<0.05)$ in IFN- $\alpha$ nonresponderCHC patients as compared to control volunteers; $0.9 \pm 0.1$ vs. $0.7 \pm 0.1$, respectively as shown in Figure $3 \mathrm{C}$. In addition, albumin levels were decreased in IFN- $\alpha$ responder and non-responder CHC patients when compared with healthy controls; $3.4 \pm 0.2,3.5 \pm 0.2$ and $3.9 \pm 0.1$, respectively as shown in Figure 3D. 


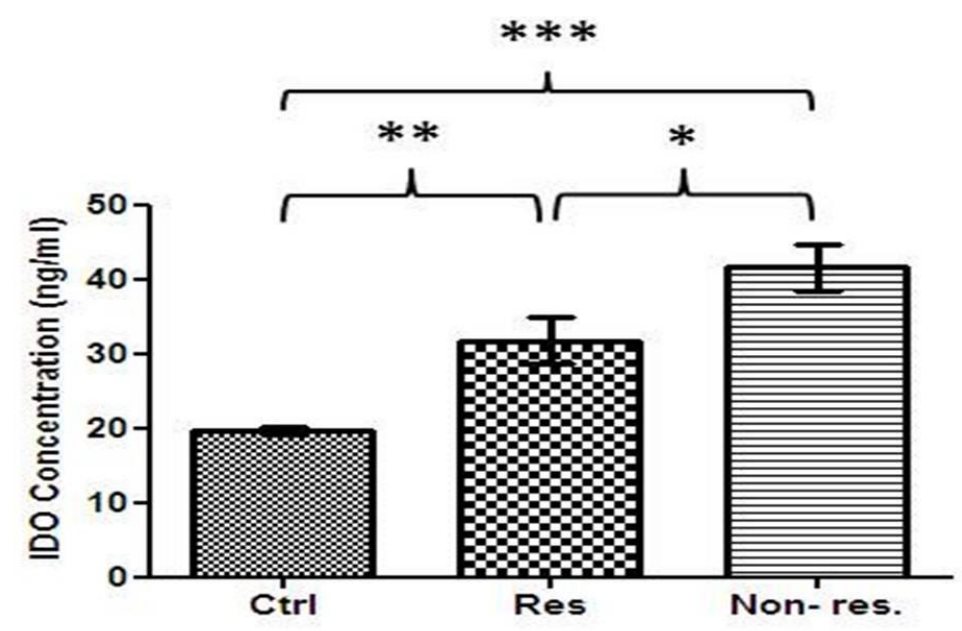

Figure 1

Figure 1: IDO Concentration in chronic HCV patients treated with IFN- $\alpha$ and ribavirin. Blood were collected from ( $\mathrm{n}=$ 15) patients with chronic HCV respond to IFN- $\alpha$ and ribavirin treatment, $(n=15)$ patients with chronic HCV didn't respond as well as $(n=10)$ samples for healthy control volunteers. * means $P<0.05$ : compared between responder and non-responder, ** means $P<0.01$ and *** means $P<0.001$ : compared with control.
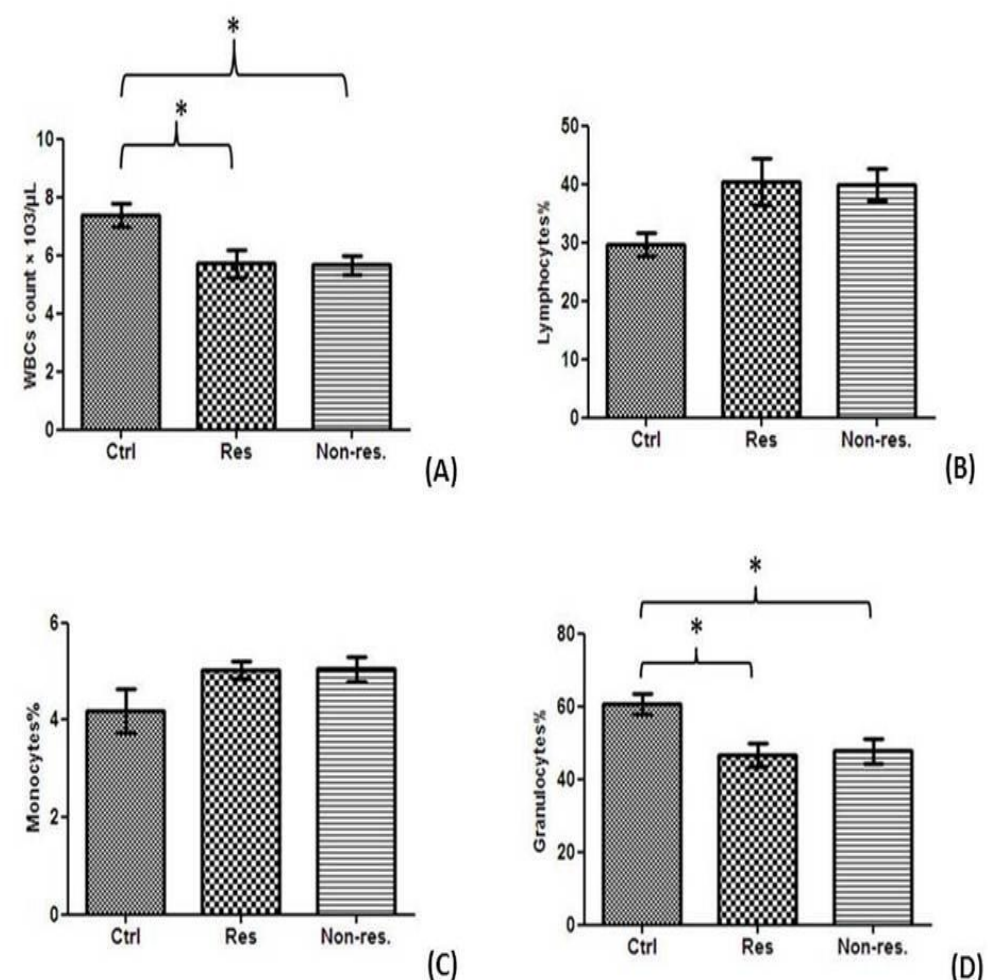

Figure 2

Figure 2:(A) representative average count of total WBCs, (B) percentages of lymphocytes, (C) percentages of Monocytes and (D) percentages of Granulocytes where blood were collected from healthy donors ( $\mathrm{n}=10$ ), patients with chronic HCV respond to IFN- $\alpha$ and ribavirin treatment $(n=15)$, and patients with chronic HCV didn't respond to treatment ( $\mathrm{n}=15)$. * means $P<0.05$ : compared with control. 

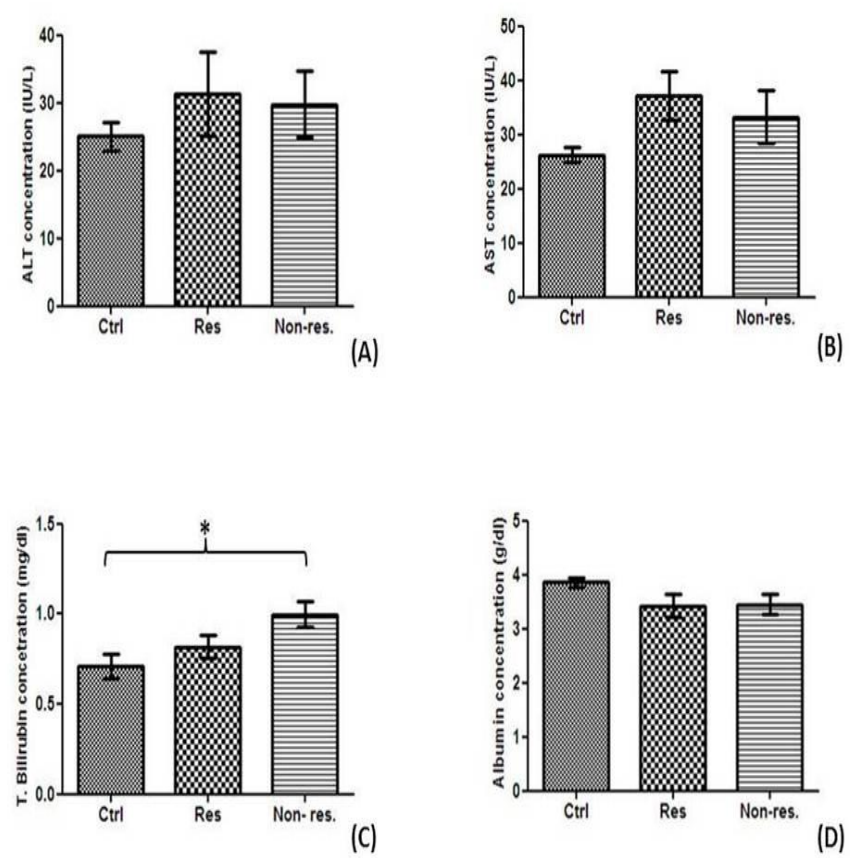

\section{Figure 3}

Figure 3: Liver function parameters in CHC patients treated with IFN- $\alpha$ and ribavirin. (A) ALT levels, (B) AST levels, (C) Total bilirubin levels, (D) Albumin levels. Blood were collected from healthy donors ( $\mathrm{n}=10$ ), patients with CHC patientsrespond to IFN- $\alpha$ and ribavirin treatment $(n=15)$, and CHC patientsdidn't respond to treatment $(n=15)$. * means $P<0.05$ : compared with control

Table 1: Comparison between CHC patient groups; responder and non-responder versus control group as regard to IDO concentration

\begin{tabular}{|c|c|c|c|}
\hline \multirow[b]{2}{*}{ IDO Concentration $(\mathrm{ng} / \mathrm{ml})$} & \multicolumn{2}{|c|}{$\mathrm{CHC}$ patients } & \multirow{2}{*}{ Healthy control } \\
\hline & Responders & Non-Responders & \\
\hline Range & 46.19 to 23.29 & 55.07 to 29.60 & 17.76 to 21.16 \\
\hline Mean \pm SD & $31.75 \pm 3.122$ & $41.55 \pm 3.056$ & $19.60 \pm 0.458$ \\
\hline$P$ value & $P<0.01$ & $P<0.001$ & \\
\hline
\end{tabular}

\section{Table 1}


Table 2:Comparison between CHC patientsgroups; IFN- $\alpha$ responder and non- responder versus control group as regard to WBCs count, lymphocytes\%, monocytes\% and granulocyte\%

\begin{tabular}{|c|c|c|c|}
\hline \multirow{2}{*}{ WBCs count $\left(\times 10^{3} / \mu \mathrm{L}\right)$} & \multicolumn{2}{|c|}{ CHC patients } & \multirow{2}{*}{ Healthy control } \\
\hline & Responders & Non-Responders & \\
\hline Range & 3.321 to 6.792 & 2.781 to 5.523 & 3.678 to 9.510 \\
\hline Mean $\pm S D$ & $5.712 \pm 0.4558$ & $5.663 \pm 0.3241$ & $7.390 \pm 0.4045$ \\
\hline Pvalue & $P<0.05$ & $P<0.05$ & \\
\hline \multirow[t]{2}{*}{ Lymphocytes \% } & \multicolumn{2}{|c|}{ CHC patients } & \multirow{2}{*}{ Healthy control } \\
\hline & Responders & Non-Responders & \\
\hline Range & 17.2 to 52.2 & 27.0 to 58.6 & 20 to 48 \\
\hline Mean $\pm S D$ & $40.35 \pm 3.946$ & $39.91 \pm 2.677$ & $29.60 \pm 2.007$ \\
\hline$P$ value & $P>0.05$ & $P>0.05$ & \\
\hline \multirow[t]{2}{*}{ Monocytes \% } & \multicolumn{2}{|c|}{ CHC patients } & \multirow{2}{*}{ Healthy control } \\
\hline & Responders & Non-Responders & \\
\hline Range & 3.9 to 4.6 & 3.3 to 5.3 & 2 to 10 \\
\hline Mean \pm SD & $5.039 \pm 0.1851$ & $5.049 \pm 0.2602$ & $4.190 \pm 0.4537$ \\
\hline Pvalue & $P>0.05$ & $P>0.05$ & \\
\hline \multirow{2}{*}{ Granulocytes \% } & \multicolumn{2}{|c|}{ CHC patients } & \multirow{2}{*}{ Healthy control } \\
\hline & Responders & Non-Responders & \\
\hline Range & 24.80 to 40.20 & 23.5 to 39.7 & 46 to 80 \\
\hline Mean $\pm S D$ & $46.57 \pm 3.238$ & $47.71 \pm 3.397$ & $60.80 \pm 2.768$ \\
\hline Pvalue & $P<0.05$ & $P<0.05$ & \\
\hline
\end{tabular}

\section{Table 2}

Table 3: Comparison between CHC patients groups; IFN- $\alpha$ responder and non- responder versus control group as regard to ALT (U/L), AST (U/L), total bilirubin concentration (mg/dl) and albumin concentration (g/dl).

\begin{tabular}{|c|c|c|c|}
\hline \multirow[t]{2}{*}{ ALT $(U / L)$} & \multicolumn{2}{|c|}{ CHC patients } & \multirow{2}{*}{ Healthy control } \\
\hline & Responders & Non-Responders & \\
\hline Range & 24 to 82 & 27 to 79 & 16 to 38 \\
\hline Mean $\pm S D$ & $31.37 \pm 6.179$ & $29.81 \pm 4.836$ & $25.10 \pm 2.111$ \\
\hline$P$ value & $p>0.05$ & $p>0.05$ & \\
\hline \multicolumn{4}{|c|}{ AST (U/L) } \\
\hline Range & 18.7 to 76 & 22 to 70 & 19 to 33 \\
\hline Mean $\pm S D$ & $37.17 \pm 4.488$ & $33.19 \pm 4.870$ & $27.04 \pm 1.036$ \\
\hline$P$ value & $p>0.05$ & $p>0.05$ & \\
\hline \multicolumn{4}{|c|}{ Total bilirubin (mg/dl) } \\
\hline Range & 0.52 to 1.0 & 0.43 to 1.33 & 0.2 to 1.2 \\
\hline Mean $\pm S D$ & $0.818 \pm 0.0667$ & $0.998 \pm 0.0691$ & $0.710 \pm 0.0706$ \\
\hline$P$ value & $p>0.05$ & $P<0.05$ & \\
\hline \multicolumn{4}{|c|}{ Albumin level (g/dl) } \\
\hline Range & 3 to 3.8 & 3.1 to 4.2 & 3.5 to 5.5 \\
\hline Mean $\pm S D$ & $3.427 \pm 0.207$ & $3.453 \pm 0.194$ & $3.860 \pm 0.08655$ \\
\hline$P$ value & $p>0.05$ & $p>0.05$ & \\
\hline
\end{tabular}

\section{Table 3}




\section{Discussion}

To shed a light on some of the mechanisms associated with the failure of chronic HCV patients to IFN-based therapy, we measured the expression of IDO, as well the total numbers of blood leukocytes and granulocytes in both responder and non-responder chronic HCV patients who were treated with interferon and ribavirin. Overall, we found increases in IDO in patients regardless the viral response to IFN/ribavirin therapy. Interestingly, the nonresponders showed higher IDO when compared to responders. Taken together, these data indicate to the presence of immunosuppressive mechanisms in HCV patients in general and in non-responders in particular. These data are of significant importance to the therapeutic approaches of HCV since it opens a new avenue to utilize or design drugs that can target these molecules as adjuvant therapy with the conventional therapy of HCV.

IDO is an immune regulatory enzyme which plays a critical role in different viral infection, human malignancies and autoimmune diseases. It enhances the immunosuppressive environment which in turn can lead to liver cirrhosis these findings are in agreement with(Barjon et al., 2015; Mehraj and Routy 2015; Asghar et al., 2015). As such, the increases in the levels of IDO in HCV patients in general than in controls and in IFN- $\alpha$ non-responders patients than responders would explain, at least in part the failure of chronic HCV patients to respond to IFN- $\alpha$.

Previous studies have shown that overexpression of IDO enhance the expansion and function of Treg and suppress T-cell proliferation via tryptophan depletion at the onset of the viral infection(Mellor and Munn 2004; Hill et al., 2007; Sharma et al., 2007; Perrella et al., 2009).

Our findings are in line with in vivo pre-clinical studies that showed a transient increase in the level of hepatic IDO in the acute $\mathrm{HCV}$ infection in chimpanzees that eliminate HCV infection spontaneously (Iwamoto et al., 2009). Moreover, high levels of IDO was detected in HCC and were significantly associated with the frequency of liver metastases(Ishio et al., 2004; Pan et al., 2008; Asghar et al., 2015). In addition, this observation was confirmed by brandacher et al(Brandacher et al. 2006)who suggest that high levels of IDO expression participate to the metastasis of colon and endometrial cancer.

(Lepiller et al. 2015) suggest that at the commencement of HCV infection, the high level of IDO may play a role in the innate antiviral immune response by retarding the replication of $\mathrm{HCV}$.

Finally, we found a significant decrease in total white blood cells and granulocytes percentage while we found increased levels of monocytes and lymphocytes percentage in IFN- $\alpha$ responder and non-responder HCV patients regardless their response to the treatment during the treatment course. This decrease may be due to chronic HCV patients who subjected to treatment with interferon and ribavirin developed leukopenia and neutropenia, because of the inhibitory effect of IFN- $\alpha$ on erythropoietin and the bone marrow, these results are consistent with other(Olariu et al., 2010; Striki et al., 2014; Jadoon et al., 2015).
This study demonstrated that an increase in both ALT and AST levels in IFN- $\alpha$ responder and non-responder patients. The infection with HCV leads to attack of the liver then make damaged to liver cells which considered one of the main causes of elevated liver enzymes, these results are in accordance with(Sarwar and Tarique 2010; Khalil and Hassan 2012). Our results indicated that there was a slight decrease in albumin levels in IFN- $\alpha$ responder and nonresponder which is due to $\mathrm{HCV}$ infection and liver failure which in turn leads to decrease the levels of albumin in the blood which leads to edema and ascites since, the liver considered the only source for producing albumin in the body, these consistent with other(Umar and DiBaise 2010; Lee 2012). In addition, there was a significant increase in total bilirubin in IFN- $\alpha$ non- responder patients when compared with IFN- $\alpha$ responders and healthy control. Furthermore, the up regulation of bilirubin levels in blood may be due the liver is not functioning correctly and may lead to scarring of the liver or cirrhosis, these results are in accordance with(Sarwar and Tarique 2010; Khalil and Hassan 2012). Our findings suggested that the expression of IDO and some biochemical markers that have immune suppressive function can be reversed and enhance responsive of HCV patients to interferon- $\alpha$ and ribavirin.

\section{References}

Afdhal, N., Zeuzem, S., Kwo, P., Chojkier, M., Gitlin, N., Puoti, M. (2014). Ledipasvir and sofosbuvir for untreated HCV genotype 1 infection. New England Journal of Medicine, 370(20), 1889-1898.

Asghar, K., Ashiq, M. T., Zulfiqar, B., Mahroo, A., Nasir, K., and Murad, S. (2015). Indoleamine 2, 3dioxygenase expression and activity in patients with hepatitis $C$ virus-induced liver cirrhosis. Experimental and Therapeutic Medicine, 9(3), 901-904.

Barjon, C., Dahlqvist, G., Calmus, Y., and Conti, F. (2015). Role of regulatory T-cells during hepatitis C infection: From the acute phase to post-transplantation recurrence.Digestive and Liver Disease, 47(11), 913917.

Brandacher, G., Perathoner, A., Ladurner, R., Schneeberger, S., Obrist, P., Winkler, C. (2006). Prognostic value of indoleamine 2, 3-dioxygenase expression in colorectal cancer: effect on tumor-infiltrating $\mathrm{T}$ cells. Clinical Cancer Research, 12(4), 1144-1151.

Comanor, L., Anderson, F., Ghany, M., Perrillo, R., Heathcote, E. J., Sherlock, C., Gordon, S. C. (2001). Transcription-mediated amplification is more sensitive than conventional PCR-based assays for detecting residual serum HCV RNA at end of treatment. The American Journal of Gastroenterology, 96(10), 2968-2972.

Cuadros, D. F., Branscum, A. J., Miller, F. D., and Abu-Raddad, L. J. (2014). Spatial epidemiology of hepatitis $C$ virus infection in Egypt: Analyses and implications. Hepatology, 60(4), 1150-1159.

Dhingra, A., Kapoor, S., and Alqahtani, S. A. (2014). Recent advances in the treatment of hepatitis C. 
Discovery medicine, 18(99), 203-208.

Hill, M., Tanguy-Royer, S., Royer, P., Chauveau, C., Asghar, K., Tesson, L., (2007). IDO expands human CD4+ CD25high regulatory $\mathrm{T}$ cells by promoting maturation of LPS-treated dendritic cells. European Journal of Immunology, 37(11), 3054-3062.

Iwamoto, N., Ito, H., Ando, K., Ishikawa, T., Hara, A., Taguchi, A., (2009). Upregulation of indoleamine 2, 3dioxygenase in hepatocyte during acute hepatitis caused by hepatitis B virus-specific cytotoxic T lymphocytes in vivo. Liver International, 29(2), 277-283.

Jadoon, S. A., Ahmed, A., Ahmad, N., and others. (2015). Effect of standard interferon and ribavirin on leukocyte count. Journal of Ayub Medical College Abbottabad, 27(2), 364-366.

Khalil, K., and Hassan, M. (2012). Predictors of Sustained Virological Response to Pegylated Interferon/Ribavirin Therapy in Chronic Hepatitis C Infected Egyptian Patients in the Northeast Provinence. The Medical Journal of Cairo University, 80(2),49-57.

Lee, J. S. (2012). Albumin for end-stage liver disease. The Korean Journal of Internal Medicine, 27(1), 13-19.

Lepiller, Q., Soulier, E., Li, Q., Lambotin, M., Barths, J., Fuchs, D., Barth, H. (2015). Antiviral and Immunoregulatory Effects of Indoleamine-2, 3Dioxygenase in Hepatitis C Virus Infection. Journal of Innate Immunity, 7(5),9-13.

Mehraj, V., and Routy, J.-P. (2015). Tryptophan Catabolism in Chronic Viral Infections: Handling Uninvited Guests. International Journal of Tryptophan Research: IJTR, 8, 41- 48.

Mellor, A. L., and Munn, D. H. (2004). IDO expression by dendritic cells: tolerance and tryptophan catabolism. Nature Reviews Immunology, 4(10), 762-774.

Mohamoud, Y. A., Mumtaz, G. R., Riome, S., Miller, D., and Abu-Raddad, L. J. (2013). The epidemiology of hepatitis C virus in Egypt: a systematic review and data synthesis. BMC Infectious Diseases, 13(1), 281- 288.

Mohd Hanafiah, K., Groeger, J., Flaxman, A. D., and Wiersma, S. T. (2013). Global epidemiology of hepatitis $\mathrm{C}$ virus infection: New estimates of age-specific antibody to HCV seroprevalence. Hepatology 57, 13331342.

Olariu, M., Olariu, C., and Olteanu, D. (2010). Thrombocytopenia in chronic hepatitis C. J Gastrointestin Liver Dis, 19(4), 381-385.

Pan, K., Wang, H., Chen, M., Zhang, H., Weng, D., Zhou, J., Xia, J. (2008). Expression and prognosis role of indoleamine 2, 3-dioxygenase in hepatocellular carcinoma. Journal of Cancer Research and Clinical Oncology, 134(11), 1247-1253.

Perrella, A., Arenga, G., Pisaniello, D., Rampone, B., Di Costanzo, G. G., Atripaldi, L., Cuomo, O. (2009). Elevated CD4+/CD25+ T-cell frequency and function during hepatitis $\mathrm{C}$ virus recurrence after liver transplantation. In Transplantation proceedings (Vol. 41, pp. 1761-1766).

Platten, M., Wick, W., and den Eynde, B. J. (2012). Tryptophan catabolism in cancer: beyond IDO and tryptophan depletion. Cancer Research, 72(21), 5435-5440.

Sarwar, S., and Tarique, S. (2010). Treatment failure in chronic hepatitis $\mathrm{C}$ : predictors other than viral kinetics. Rawal Medical Journal, 35(2), 217-220.

Shaker, E., Mahmoud, H., and Mnaa, S. (2010). Silymarin, the antioxidant component and Silybum marianum extracts prevent liver damage. Food and Chemical Toxicology, 48(3), 803-806.

Sharma, M. D., Baban, B., Chandler, P., Hou, D.-Y., Singh, N., Yagita, H., ... Munn, D. H. (2007). Plasmacytoid dendritic cells from mouse tumor-draining lymph nodes directly activate mature Tregs via indoleamine 2, 3-dioxygenase.The Journal of clinical investigation, 117(9), 2570-2582.

Striki, A., Manolakopoulos, S., Deutsch, M., Mela, M., Kalafateli, M., Schini, M., (2014). Cirrhosis but not neutropenia is associated with the development of infection in patients with chronic hepatitis $\mathrm{C}$ undergoing treatment with pegylated interferon-alpha and ribavirin. Journal of Viral Hepatitis, 21(9), 624-632.

Trembling, P. M., Tanwar, S., Rosenberg, W. M., and Dusheiko, G. M. (2013). Treatment decisions and contemporary versus pending treatments for hepatitis C. Nature Reviews Gastroenterology \& Hepatology, 10(12), 713-728.

Umar, S. B., and DiBaise, J. K. (2010). Proteinlosing enteropathy: case illustrations and clinical review. The American Journal of Gastroenterology, 105(1), 43-49.

Vasudevan, A., and Lubel, J. S. (2015). New-onset of celiac disease during interferon-based therapy for hepatitis C. Gastroenterology Report, 3(1), 83-85.

Yeung, A. W. S., Wu, W., Freewan, M., Stocker, R., King, N. J. C., and Thomas, S. R. (2012). Flavivirus infection induces indoleamine 2, 3-dioxygenase in human monocyte-derived macrophages via tumor necrosis factor and NF-кB. Journal of Leukocyte Biology, 91(4), 657-666.

Yu, J., Du, W., Yan, F., Wang, Y., Li, H., Cao, S., Ren, X. (2013). Myeloid-derived suppressor cells suppress antitumor immune responses through IDO expression and correlate with lymph node metastasis in patients with breast cancer. The Journal of Immunology, 190(7), 3783-3797.

Yu, J., Sun, J., Wang, S. E., Li, H., Cao, S., Cong, Y., ... Ren, X. (2011). Upregulated expression of indoleamine 2, 3-dioxygenase in primary breast cancer correlates with increase of infiltrated regulatory $\mathrm{T}$ cells in situ and lymph node metastasis. Clinical and Developmental Immunology, 2011, 1-10. 